\title{
New Approach for the Analysis of Isotopic Composition in Precipitation Globally
}

\section{BP Singh}

School of Engineering and Technology, Amity University, Bijwasan, New Delhi-110 061, India

*Corresponding author: BP Singh, School of Engineering and Technology, Amity University, Bijwasan, New Delhi-110 061, India, Tel: +(91)-11-28061487; E-mail: bpsingh@amity.edu

Rec date: Jan 21, 2016; Acc date: Feb 02, 2016; Pub date: Feb 10, 2016

Copyright: ( 2016 Singh BP. This is an open-access article distributed under the terms of the Creative Commons Attribution License, which permits unrestricted use, distribution, and reproduction in any medium, provided the original author and source are credited.

\begin{abstract}
Isotopic composition of hydrogen and oxygen of water in precipitation is important tool to analyze the water in hydrological cycle. A new method has been suggested by Singh [7] plotting slope versus intercept of local meteoric water line (LMWL) to find the original isotopic composition in precipitation as injected tracer globally. Singh [8-10] has applied these concepts to analyze the isotopic composition in precipitation in different catchment areas of river and different seasons, precipitation falling at different altitudes in a region or a place and across the continent.
\end{abstract}

These studies are extended for the (a) study of changing intercept but keeping the same slope as attributed to changed conditions as the source of atmospheric moisture. The experimental data as available of two transect from Amazon to Altiplano in South America are analyzed. The results are presented assigning two components, one due to Rayleigh adiabatic condensation process rainfall and second recycled water vapour by evotranspiration. The details of the analysis are given and the results clearly indicate these two components, are discussed in detail.

(b) Study of higher intercept due to mediterranean meteoric water line (MMWL), Israel samples from various inputs on mountains, coastal area, caves and valley to ascertain the precipitation is from the same source.

(c) Study of LMWL across the country (India) for four different regions to obtain the LMWL of the regions by the method of Singh [7] obtained the original isotopic composition of water in all the four regions thereby get the global meteoric water line (GMWL).

Keywords: Isotope; Hydrology; Precipitation

\section{Introduction}

The stable isotopes of water molecule $\left(\mathrm{H}_{2}{ }^{16} \mathrm{O},{ }^{1} \mathrm{H}^{2} \mathrm{H}^{16} \mathrm{O}, \mathrm{H}_{2}{ }^{18} \mathrm{O}\right)$ are powerful tracers in hydrosphere and hydrologic cycle. There are as many as 9 isotopic configuration of water which is distinguishably due to their masses and therefore, these can be used as tracers. However, we have mass spectrometers and we can measure the ratio of the isotopes i.e., ${ }^{2} \mathrm{H} /{ }^{1} \mathrm{H}$ and ${ }^{18} \mathrm{O} /{ }^{16} \mathrm{O}$ of the precipitation. This can be expressed as $\delta^{2} \mathrm{H}$ and $\delta^{18} \mathrm{O}$ where $\delta_{\text {sample }}=\left(\mathrm{R}_{\text {sample }} / \mathrm{R}_{\mathrm{SMOW}}-1\right) 1000$ where $\mathrm{R}={ }^{2} \mathrm{H} /{ }^{1} \mathrm{H}$ or ${ }^{18} \mathrm{O} /{ }^{16} \mathrm{O}$. Craig [1] showed that the interrelationship between $\delta^{2} \mathrm{H}$ and $\delta^{18} \mathrm{O}$ in precipitation is virtually independent of temperature all over the globe and follows a simple, linear formula: the so called "Global Meteoric Water Line (GMWL)". The average relationship is $\delta^{2} \mathrm{H}=8 \delta^{18} \mathrm{O}+10 \%$. This line usually only covers negative values of $\delta^{2} \mathrm{H}$ and $\delta^{18} \mathrm{O}$ i.e., water that is more depleted in heavy isotopes than the Vienna sea mean ocean water (VSMOW) standard. This is because all rainwater originates in some type of evaporation process. Therefore, with very rare exception, it is more depleted than sea water.

The plot of $\delta^{2} \mathrm{H}$ and $\delta^{18} \mathrm{O}$ giving linear equation with slope and intercept are being studied globally through the network known as Global Network for Isotopes in Precipitation (GNIP) established in collaboration between International Atomic Energy Agency (IAEA) and World Meteorological Organization (WMO). With these studies the GMWL is modified as taken to be $\delta^{2} \mathrm{H}=8.13 \delta^{18} \mathrm{O}+10.8 \%$ o by Rozanski et al. [2]. This has been discussed experimentally and theoretically by various investigators Craig [1], Friedman [3], Dansgaard [4], Yurtsever [5] and Singh and Kumar [6].

Lot of studies have been done and plots are as available of $\delta^{2} \mathrm{H}$ versus $\delta^{18} \mathrm{O}$ in various environmental conditions in a region and in different locations i.e., river, ponds, surface water and other ground water bodies and plots are also available between $\delta^{2} \mathrm{H}$ versus $\delta^{18} \mathrm{O}$ at different places and these are popularly known as Local Meteoric Water Line (LMWL).

One of the concepts of slope and intercept are not taken together and their correlation. Singh [7-11] had taken up the studies of various environmental conditions in typical cases but these are more case studies (a) when slope and intercept do not fall on straight line (b) when the data set in region are scattered around the straight line (c) when the original isotopic compositions are different in big regions, they do fall on GMWL. With these motivation case studies are taken up to ascertain the usefulness of the plot of slope versus intercept. This is the main consideration for this new approach.

\section{Method of interpretation of the data}

We plot $\delta^{18} \mathrm{O}$ versus $\delta^{2} \mathrm{H}$, the isotopic composition of the precipitation from different environmental conditions taking $\delta^{18} \mathrm{O}$ on $\mathrm{x}$-axis and $\delta^{2} \mathrm{H}$ on $\mathrm{y}$-axis i.e., $\delta^{2} \mathrm{H}=\mathrm{m} \delta^{18} \mathrm{O}+\mathrm{c}$ in $\mathrm{x}$-y plane. We get the straight line with the slope of $\mathrm{m}_{1}, \mathrm{~m}_{2}, \mathrm{~m}_{3}$ etc. corresponding to 
intercept $c_{1}, c_{2}, c_{3}$ etc. These plots are in different environmental conditions in a region for the same source of precipitation at different time. These are straight lines normally very close to each other and do not intersect. Is there any correlation between slopes $\mathrm{m}_{1}, \mathrm{~m}_{2}, \mathrm{~m}_{3}$ etc. and intercept $c_{1}, c_{2}, c_{3}$ ? This is the main point for this analysis if we plot again, $\mathrm{m}_{1}, \mathrm{~m}_{2}, \mathrm{~m}_{3}$ corresponding $\mathrm{c}_{1}, \mathrm{c}_{2}, \mathrm{c}_{3}$ etc. that is we are in $\mathrm{m}-\mathrm{c}$ plane. These points on $\mathrm{m}-\mathrm{c}$ plane may be scattered in the plot but if we get all the points on straight line within a statistical error and take slope $\mathrm{p}$ and intercept $\mathrm{q}$ of the straight line then we write down the equation $\mathrm{c}=\mathrm{pm}+\mathrm{q}$ in $\mathrm{m}-\mathrm{c}$ plane similar to $\delta^{2} \mathrm{H}=\mathrm{m} \delta^{18} \mathrm{O}+\mathrm{c}$ in the $\mathrm{x}-\mathrm{y}$ plane. If the points are scattered in $\mathrm{m}-\mathrm{c}$ plane and not on one straight line then there may not be any correlation, if these points are on straight line there may be correlation. We rewrite the equation $\mathrm{q}=-\mathrm{pm}$ $+\mathrm{c}$ now comparing with this equation with $\delta^{2} \mathrm{H}=\mathrm{m} \delta^{18} \mathrm{O}+\mathrm{c}$ we get $\mathrm{p}$ is $\delta^{18} \mathrm{O}$ and $\mathrm{q}$ is $\delta^{2} \mathrm{H}$. This $\mathrm{p}, \mathrm{q}$ is the isotopic composition corresponding to slope $\mathrm{m}$ and corresponding intercept $\mathrm{c}$. If this $\mathrm{p}, \mathrm{q}$ is isotopic composition of precipitation on the GMWL then we can conclude that this is the original isotopic composition. This is modified by the kinetic fractionation due to temperature and environmental conditions as we get LMWL.

We can look the same problem by different method to interpret the experimental data. We consider GMWL for meteoric water as suggested by Craig [2] and finally adopted as given by Razanski et al. [1] to be $\delta^{2} \mathrm{H}=8.13 \delta^{18} \mathrm{O}+10.8$.

Let us take the water of different isotopic compositions and take different slopes similar to those of LMWL for example 7.4-8.1 and calculate the intercept by the equation $\delta^{2} \mathrm{H}=$ slope $\delta^{18} \mathrm{O}$ (x-axis) +intercept (y-axis)\%o (1).

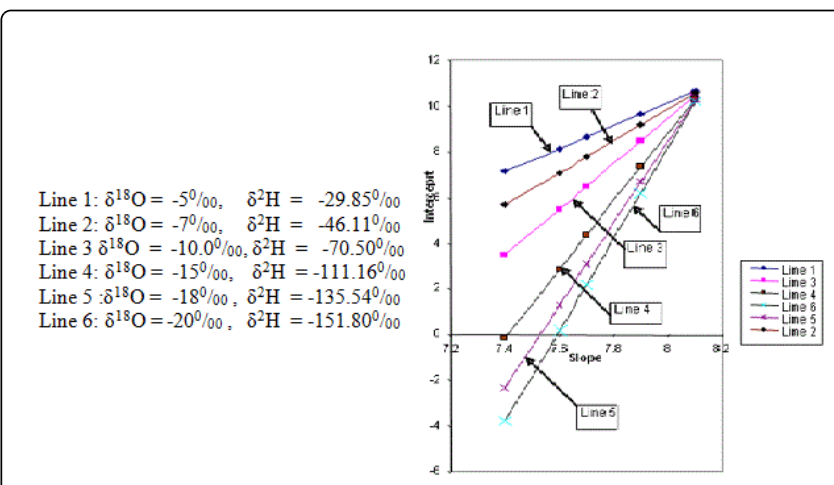

Figure 1: Intercept on $\delta^{2} \mathrm{H}$ axis versus the theoretical values of the slope of $\delta^{2} \mathrm{H}$ and $\delta^{18} \mathrm{O}$ plot for different water having $\delta^{18} \mathrm{O}$ from -5 to $-20 \%$ corresponding values of $\delta^{2} \mathrm{H}$ as given by line 1 to line 6 .

Thus these slopes are calculated with intercept for different isotopic compositions of water as given in Table 1, are plotted as shown in Figure 1. The different lines 1 to 6 in the plot are straight lines for different isotope compositions of water and therefore, the plot of experimental slopes versus intercept of $\delta^{2} \mathrm{H}$ axis is suggestive that if it is a straight line, this should correspond to isotopic composition of water in precipitation. This is modified due to environmental conditions (temperature and humidity). Therefore what we record is LMWL. Therefore, the plot of experimental slopes on $\mathrm{x}$-axis versus intercepts on $y$-axis shall result in the isotopic composition of water as per Eq. (1), which is the water of the precipitation to be on GMWL thereby we get $\delta^{18} \mathrm{O}$ and $\delta^{2} \mathrm{H}$. This is the basis of interpretation of data. In the present analysis the change in slopes for each LMWL are small however, the change of intercepts are large. This can be seen from Table 1 for slopes 7.4 to 8.1 , intercepts are -3.8 to 10.2 for 6 th line.

\begin{tabular}{|c|c|c|c|c|c|c|}
\hline \multirow{2}{*}{$\begin{array}{l}\text { Lines for different } \\
\text { isotopic } \\
\text { composition } \\
\text { slope }\end{array}$} & \multicolumn{6}{|c|}{ Intercept } \\
\hline & 1 & 2 & 3 & 4 & 5 & 6 \\
\hline 7.4 & 7.15 & 5.3 & 3.5 & -0.15 & -2.34 & -3.8 \\
\hline 7.6 & 8.15 & 7.1 & 5.5 & 2.85 & 1.3 & 0.2 \\
\hline 7.7 & 8.65 & 7.8 & 6.5 & 4.35 & 3.1 & 2.84 \\
\hline 7.9 & 9.65 & 9.19 & 8.5 & 7.35 & 6.7 & 6.2 \\
\hline 8.1 & 10.65 & 10.6 & 10.5 & 10.35 & 10.3 & 10.2 \\
\hline
\end{tabular}

Table 1: Slopes/intercept using relation $\delta^{2} \mathrm{H}=$ slope $\delta^{18} \mathrm{O}+$ intercept for the water.

\section{Case study 1}

Gonfiantini et al. [12] have reported the isotopic composition of yearly and monthly precipitation sample as collected at various altitudes and in two transits from the Amazon to the Altiplano in Bolivia, South America and plotted LMWL in all these locations with varying slopes and intercepts in these regions. Singh [7] has given a new method for interpretation to get the original isotopic composition of water in precipitation by plotting slope versus intercept. The data as given by Gonfiantini et al. [12] has been re-examined by this plot especially to understand the varying intercept for the almost same slopes in these measurements to come out with certain explanation.

\section{Precipitation regime and sampling size}

Precipitation samples were collected in stations along two transits between the latitudes $14^{\circ} 30^{\prime}$ and $17^{\circ} 30 \mathrm{~S}$ and the longitudes $64^{\circ} 30$ and $68^{\circ} \mathrm{W}$. These samples were analyzed to get $\delta^{2} \mathrm{H}$ and $\delta^{18} \mathrm{O}$ at various heights as given by Gonfiantini et al. [12]. All details are available for altitude, amount of precipitation mean surface temperature of all the stations as reported by Gonfiantini et al. [12]. The laboratory measurement for isotopic were analyzed at Universite de Paris and relationship between $\delta^{2} \mathrm{H}$ and $\delta^{18} \mathrm{O}$ has been established at different stations and the monthly values are presented in Yungas - Altiplano Transit, Bolivia. All detailed analysis and modeling had been done by Gonfiantini et al. [12]. The analysis is done in this present studies for Yungas-Altiplano Transit at Bolivia to understand the intercept differences with virtually identical slope.

\section{Analysis of the data}

The data as reported different stations at different altitudes for $\delta^{2} \mathrm{H}$ and $\delta^{18} \mathrm{O}$ are reported for various stations in transect between Yungas and Altiplano for different stations as given by Gonfiantini et al. [12] and we obtained LMWL as given below Table 2:

\begin{tabular}{|l|l|l|l|}
\hline S. No & $\begin{array}{l}\text { Altitude in } \\
\text { m.a.s.I }\end{array}$ & $\begin{array}{l}\text { Name of the } \\
\text { station }\end{array}$ & LMWL \\
\hline 1 & 300 & Rurrenabaque & $\delta^{2} \mathrm{H}=8.62 \delta^{18} \mathrm{O}+11.32 \%, \mathrm{R}^{2}=0.99$ \\
\hline 2 & 395 & Sapecho & $\delta^{2} \mathrm{H}=8.55 \delta^{18} \mathrm{O}+11.84 \%, \mathrm{R}^{2}=0.98$ \\
\hline 3 & 600 & Caranavi & $\delta^{2} \mathrm{H}=8.65 \delta^{18} \mathrm{O}+13.28 \%, \mathrm{R}^{2}=0.99$ \\
\hline
\end{tabular}


Citation: BP Singh (2016) New Approach for the Analysis of Isotopic Composition in Precipitation Globally. Hydrol Current Res 7: 225. doi: $10.4172 / 2157-7587.1000225$

Page 3 of 7

\begin{tabular}{|l|l|l|l|}
\hline 4 & 1700 & Coroico & $\delta^{2} \mathrm{H}=8.46 \delta^{18} \mathrm{O}+18.03 \%, \mathrm{R}^{2}=0.99$ \\
\hline 5 & 2200 & Sacramento & $\delta^{2} \mathrm{H}=8.41 \delta^{18} \mathrm{O}+18.90 \%, \mathrm{R}^{2}=0.99$ \\
\hline 6 & 3100 & Chuspipata & $\delta^{2} \mathrm{H}=8.47 \delta^{18} \mathrm{O}+21.46 \%, \mathrm{R}^{2}=0.98$ \\
\hline 7 & 4040 & Pongo & $\delta^{2} \mathrm{H}=8.43 \delta^{18} \mathrm{O}+22.03 \%, \mathrm{R}^{2}=0.99$ \\
\hline 8 & 4650 & La Cumbre & $\delta^{2} \mathrm{H}=8.06 \delta^{18} \mathrm{O}+18.12 \%, \mathrm{R}^{2}=0.99$ \\
\hline 9 & 5200 & Chacaltaya & $\delta^{2} \mathrm{H}=8.10 \delta^{18} \mathrm{O}+19.32 \%, \mathrm{R}^{2}=0.99$ \\
\hline 10 & 4080 & El Alto & $\delta^{2} \mathrm{H}=8.37 \delta^{18} \mathrm{O}+21.73 \%, \mathrm{R}^{2}=0.99$ \\
\hline
\end{tabular}

Table 2: Different altitudes for $\delta^{2} \mathrm{H}$ and $\delta^{18} \mathrm{O}$.

The plot of these LMWL at different stations is given in Figures 2a and $2 \mathrm{~b}$. These are straight lines but very close to each other and almost parallel thus indicating that slopes are almost same but intersect is varying on $\delta^{2} \mathrm{H}$ axis from 11 to 22 . It also indicates that there are two groups with intercept at $\sim 11$ and other with intercept at $\sim 21$. As per analysis as given by Singh [7], the author plotted slope and intercept of all the observations as given in Figure 3 indicating three groups at lower altitude (300 m.a.s.l. to 600 m.a.s.l., middle altitude (1700 m.a.s.l. to 22 m.a.s.l.) and high altitude (3100 m.a.s.l. to 4080 m.a.s.l.) and these groups are shown in Figure 3.

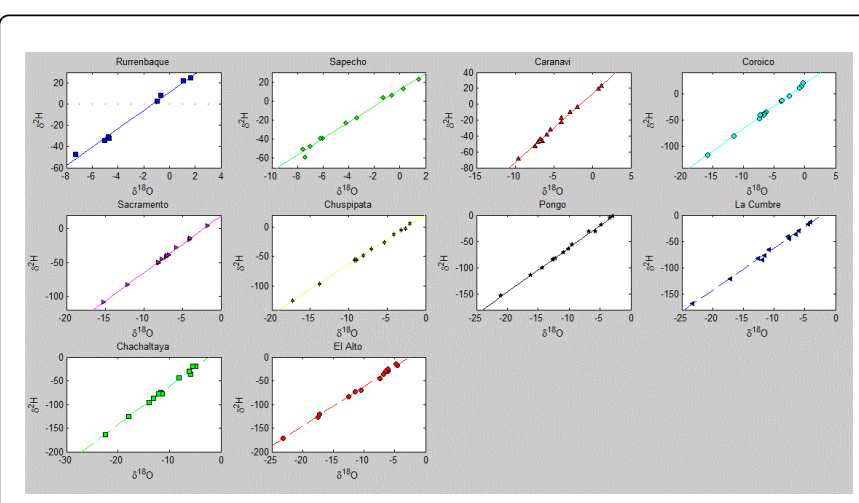

Figure 2a: The plot of ${ }^{18} \mathrm{O}$ versus ${ }^{2} \mathrm{H}$ for all the stations giving linear relations as given in Table 2.

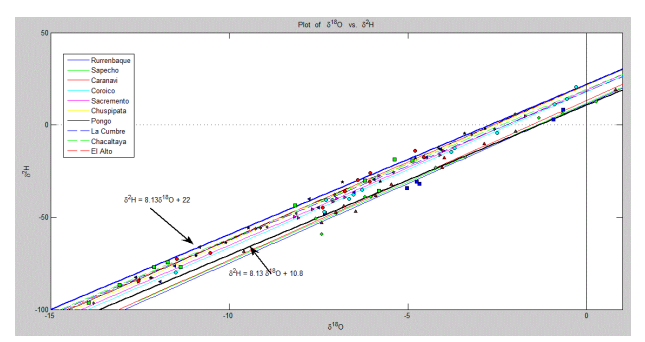

Figure 2b: Plot of $\delta^{2} \mathrm{H}$ versus $\delta^{18} \mathrm{O}$. All the lines are very close to each other and parallel.

Another plot as given in Figure 4 between slope versus intercept for altitudes from 3100 m.a.s.l. to 4080 m.a.s.l. which is straight line giving, the $y=8.80 x-53.24 \%$ o $R^{2}=0.9992$ by the method of least square fit. As per interpretation of Singh if this is a straight line that all the observations of $\delta^{2} \mathrm{H}$ and $\delta^{18} \mathrm{O}$ measurement are correlated and by rewriting this equation we get $-53.24=-8.80 \mathrm{x}+\mathrm{y} \%$ and therefore $\delta^{2} \mathrm{H}=-53.24 \%$ and $\delta^{18} \mathrm{O}=-8.88 \%$. This is on GMWL i.e., $\delta^{2} \mathrm{H}=8.13 \delta^{18} \mathrm{O}+22$ i.e., an original isotopic composition without any modification. This is not so, for the altitudes at 1700 m.a.s.l. to 2100 m.a.s.l. and also for the altitudes at 3100 m.a.s.l

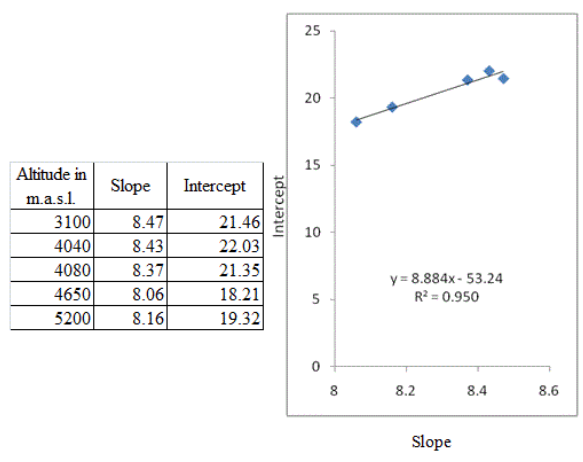

Figure 4: It gives the plot of slope versus intercept for different altitudes from 3100-5200 m.a.s.l.

\section{Discussion}

Gonfiantini et al. [12] had suggested the precipitation at lower altitudes may be due to evaporation in the region.

The plot of slope versus intercept of LMWL as given by Singh [7] had given additional information and also confirmation of argument that precipitation had different origin.

(i) Precipitation falling at different altitude above 3010 to 4080 m.a.s.l. are correlated each other as we got straight line giving the value of $\delta^{18} \mathrm{O}=-8.88 \%$ and $\delta^{2} \mathrm{H}=-53.24 \%$ o to be taken original isotopic composition of precipitation.

This is on GMWL? The GMWL taking as given by Rozanski et al. [1] is $\delta^{2} \mathrm{H}=8.13 \delta^{18} \mathrm{O}+10.8 \%$ taking $\delta^{18} \mathrm{O}=-8.88 \%$ we get $\delta^{2} \mathrm{H}=-61.34 \%$ but if we take $\delta^{2} \mathrm{H}=8.13 \delta^{18} \mathrm{O}+22 \%$ as given by Ayalon 
Page 4 of 7

et al. [13] and also by Dansgaard [4], Gat and Dansgaard [14] due to influenced the origin of storm and evaporation effect of Mediterranean type situation, most of the precipitation are affected giving intercept to be $\sim 22 \%$. If this is GMWL than taking $\delta^{18} \mathrm{O}=-8.88 \%$ o then $\delta^{2} \mathrm{H}=-50.19 \%$, while the observed value is $\delta^{2} \mathrm{H}=-53.24 \%$ o which is within statistical error $\sim 2.0 \%$. Therefore, we take $\delta^{2} \mathrm{H}=8.13 \delta^{18} \mathrm{O}+22 \%$ o as GMWL, Gonfiantini et al. [12] as reported that the varying intercept with same slope attributed to changing conditions at source / atmosphere moisture as given by Ayalon [13].

(ii) Therefore, by this method of the plot of slope versus intercept, we could able to identify the component of precipitation at higher altitudes. The plot at lower altitude in Figures $2 a$ and $2 b$, this component had different origin. Gonfiantini et al. [12] had suggested that at low altitudes, the slope is less pronounced may be due to vapour recycled by evotranspiration (Salati et al. [15]; Gat and Matsui [16]). This is important in Amazon region as system recycled vapour is isotopic identical to rainfall and heavier than left in the system so counteracting the heavy isotopes. This may also partly be affected in mid altitude region.

Therefore, we conclude that the plot of slope versus intercept of different LMWL in the small region is useful tool to analyze the isotopic composition of precipitation and its origin.

\section{Case study 2}

Avner et al. [13] had published rainfall isotopic characteristic of water at various sites in Israel giving all the details i.e., $\delta^{18} \mathrm{O}, \delta^{2} \mathrm{H}$, rainfall, elevation, temperature for a long period from 1995-2003. They analyzed the data and concluded that the plot of $\delta^{2} \mathrm{H}$ and $\delta^{18} \mathrm{O}$ fall close to mediterranean meteoric water line (MMWL) rather GMWL. They also concluded that $\delta^{2} \mathrm{H}$ and $\delta^{18} \mathrm{O}$ close to MMWL typical of relative massive rain event above $10-15 \mathrm{~mm}$ during mid-water at the surface temperature of $5^{\circ}-10^{\circ} \mathrm{C}$. They also concluded that rainfall with less than $10 \mathrm{~mm}$ have slope less 8 and intercept also less than 22 as a consequence of evaporation process beneath the clouds. They discussed the variation of slopes around 8 and intercept of $\delta^{2} \mathrm{H}$ axis at various sites in Israel at various heights and also different intensity of rains and temperatures, isotopic composition of eastern, central and western area of Israel.

Cloud formation and raining in a small territory from the evaporation process of Mediterranean may not differ significantly but $\delta^{2} \mathrm{H}$ and $\delta^{18} \mathrm{O}$ at various sites may have some correlation, therefore it is important to re-analyze the data and look for any correlation of $\delta^{2} \mathrm{H}$ and $\delta^{18} \mathrm{O}$ at a location, at different elevation with varying rainfall and also in different local conditions.

This is the main objective for this analysis.

\section{Study area and the method}

The study focuses measurement of $\delta^{18} \mathrm{O}, \delta^{2} \mathrm{H}$ using VG. SIRA-II mass spectrometer with accuracy of $0.1 \%$ for $\delta^{18} \mathrm{O}$ and $1.0 \%$ for $\delta^{2} \mathrm{H}$. Data on air temperature were obtained since 1990 and rain water was collected by allowing water to accumulate in a large funnel and allowed to drop narrow head bottle not to evaporate during collection. The rainfall water collected is divided in different years for the following areas:

(a) Rainfall and snow in Hermon at two sites Neve and Ativ and lower cable. (b) Easter sites of central mountain at Alon and Ma'ale central mountain ridge

(c) Arava valley at Nahal Hazera Valley

(d) Central plane Bet Dagan, Haifa Port and Ashdod

(e) Samaria mountain at City of Ashdod

(f) Jeruselam

(g) Galibe mount Peqiin and Mikhmanim

(h) Samaria mountain

The data thus obtained are plotted between $\delta^{2} \mathrm{H}$ and $\delta^{18} \mathrm{O}$ at various sites at different dates with year indicating different elevations, also different rainfall conditions and obtained LMWL as given in Table 3 with statistical errors. The plots were done between $\delta^{18} \mathrm{O}$ and $\delta^{2} \mathrm{H}$ and obtained LMWL at different slopes as given below.

\begin{tabular}{|l|l|l|}
\hline S. No & $\begin{array}{l}\text { Plot of LMWL at site } \\
\text { given below }\end{array}$ & $\begin{array}{l}\delta^{18} \text { and } \delta^{2} \mathrm{H} \text { relationship local } \\
\text { meteoric water line }(\mathrm{LMWL})\end{array}$ \\
\hline 1 & Hermon & $\delta^{2} \mathrm{H}=6.02 \delta^{18} \mathrm{O}+11.30 \%, \mathrm{R}^{2}=0.95$ \\
\hline 2 & Neve Ativ & $\delta^{2} \mathrm{H}=7.81 \delta^{18} \mathrm{O}+22.54 \%, \mathrm{R}^{2}=0.87$ \\
\hline 3 & Maale Efrayim & $\delta^{2} \mathrm{H}=5.09 \delta^{18} \mathrm{O}+11.54 \%, \mathrm{R}^{2}=0.68$ \\
\hline 4 & Alon & $\delta^{2} \mathrm{H}=7.13 \delta^{18} \mathrm{O}+11.95 \%, \mathrm{R}^{2}=0.92$ \\
\hline 5 & Ariel & $\delta^{2} \mathrm{H}=6.43 \delta^{18} \mathrm{O}+14.91 \%, \mathrm{R}^{2}=0.77$ \\
\hline 6 & Haifa Port & $\delta^{2} \mathrm{H}=6.63 \delta^{18} \mathrm{O}+10.47 \%, \mathrm{R}^{2}=0.92$ \\
\hline 7 & Bet Dagan & $\delta^{2} \mathrm{H}=4.96 \delta^{18} \mathrm{O}+6.45 \%, \mathrm{R}^{2}=0.65$ \\
\hline 8 & Mevasseret Zion & $\delta^{2} \mathrm{H}=5.27 \delta^{18} \mathrm{O}+4.88 \%, \mathrm{R}^{2}=0.75$ \\
\hline 9 & Ashdod & $\delta^{2} \mathrm{H}=5.03 \delta^{18} \mathrm{O}+11.31 \%, \mathrm{R}^{2}=0.86$ \\
\hline 10 & Jerusalem and Soreq & $\delta^{2} \mathrm{H}=6.73 \delta^{18} \mathrm{O}+17.33 \%, \mathrm{R}^{2}=0.91$ \\
\hline 11 & Jerusalem and Soreq & $\delta^{2} \mathrm{H}=7.26 \delta^{18} \mathrm{O}+21.52 \%, \mathrm{R}^{2}=0.75$ \\
\hline 12 & Peqi'in & $\delta^{2} \mathrm{H}=7.07 \delta^{18} \mathrm{O}+17.21 \%, \mathrm{R}^{2}=0.88$ \\
\hline 13 & Mikhmanim & $\delta^{2} \mathrm{H}=7.72 \delta^{18} \mathrm{O}+17.19 \%, \mathrm{R}^{2}=0.88$ \\
\hline 14 & Makhtesh Qatan & $\delta^{2} \mathrm{H}=8.23 \delta^{18} \mathrm{O}+21.60 \%, \mathrm{R}^{2}=0.68$ \\
\hline 15 & Shikmona & $\delta^{2} \mathrm{H}=5.75 \delta^{18} \mathrm{O}+9.10 \%, \mathrm{R}^{2}=0.88$ \\
\hline 16 & Soreq caves & $\delta^{2} \mathrm{H}=5.32 \delta^{18} \mathrm{O}+6.08 \%, \mathrm{R}^{2}=0.85$ \\
\hline 17 & Soreq caves & $\delta^{2} \mathrm{H}=7.53 \delta^{18} \mathrm{O}+20.59 \%, \mathrm{R}^{2}=0.87$ \\
\hline 19 & Soreq caves & $\delta^{2} \mathrm{H}=6.10 \delta^{18} \mathrm{O}+10.49 \%, \mathrm{R}^{2}=0.83$ \\
\hline & Soreq caves & $\delta^{2} \mathrm{H}=7.19 \delta^{18} \mathrm{O}+20.05 \%, \mathrm{R}^{2}=0.84$ \\
\hline
\end{tabular}

Table 3: Different rainfall conditions and obtained LMWL. 
Citation: BP Singh (2016) New Approach for the Analysis of Isotopic Composition in Precipitation Globally. Hydrol Current Res 7: 225. doi: $10.4172 / 2157-7587.1000225$

Page 5 of 7

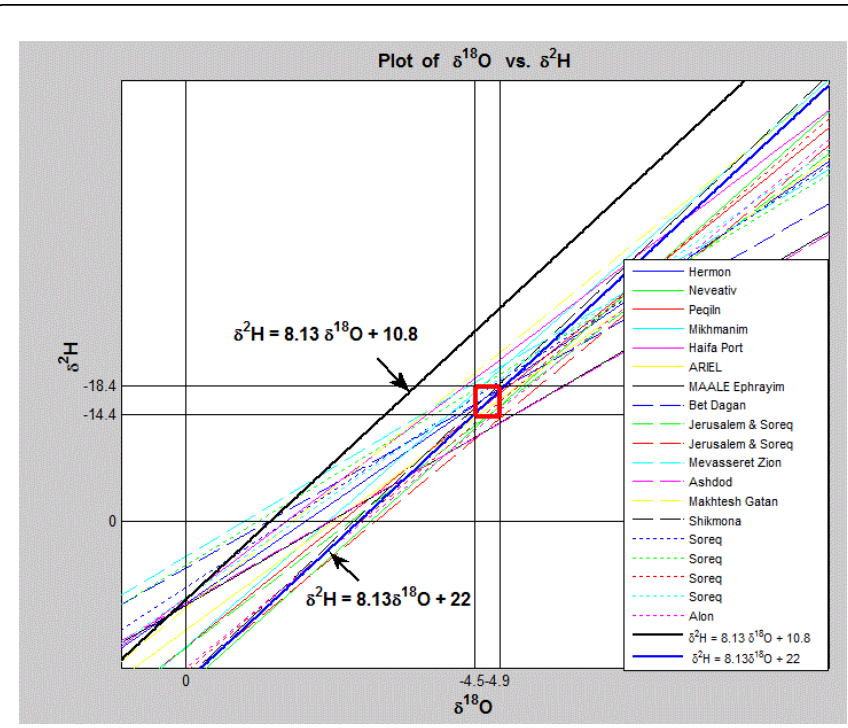

Figure 5: The plot of $\delta^{2} \mathrm{H}$ versus $\delta^{18} \mathrm{O}$ for various locations in Israel along with LMWL and MMWL. The rectangle is shown which is close to MMWL.
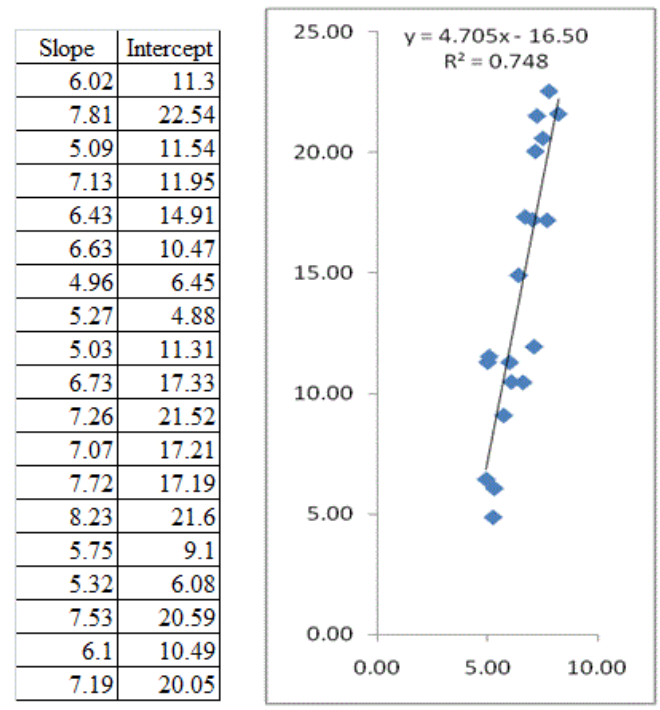

Figure 6: Showing the plot of slope versus interept of LMWL of 19 States getting $\mathrm{y}=4.7 \mathrm{x}+16.50 \%$ or $\quad-16.50=-4.70 \quad \delta^{18} \mathrm{O}+\mathrm{y}$ i.e., $\delta^{18} \mathrm{O}=-4.7 \%$ and $\delta^{2} \mathrm{H}=-16.50 \%$.

The plot of $\delta^{18} \mathrm{O}$ versus $\delta^{2} \mathrm{H}$ is shown in Figure 5 with different colours. We have also shown the plot of $\delta^{2} \mathrm{H}=8.13 \delta^{18} \mathrm{O}+10.8$ i.e., (GMWL) and $\delta^{2} \mathrm{H}=8.13 \delta^{18} \mathrm{O}+22 \%$ (MMWL) as shown in same Figure 5. All these lines are conversing and then diverging. Another plot is done as shown in Figure 6 between the slopes versus intercepts for all the 19 stations which is shown in Figure 6 within this $\mathrm{R}^{2}=0.748$ marked by rectangle which is more close to MMWL. This is straight line that is to say the locations of different precipitation in different places are correlated. We get original water composition by $\mathrm{y}=4.70 \mathrm{x}-16.50 \% 0 \quad$ or $\quad-16.50 \mathrm{x}=-4.70 \mathrm{x}+\mathrm{y} \quad$ i.e., $\quad \delta^{18} \mathrm{O}=-4.70 \%$ and $\delta^{18} \mathrm{O}=-16.50 \%$.

It is concluded that (i) the plot of $\delta^{2} \mathrm{H}$ versus $\delta^{18} \mathrm{O}$ is a straight line therefore the original composition of the precipitation at different area of Israel has a same origin and the original isotopic composition has been obtained by this method.

The poor $\mathrm{R}^{2}$ in this study may be due to many parameters like different locations, mountains, caves, intensity of rainfall and temperature.

\section{Case study 3}

Kumar et al. [17] had reported the isotopic composition of precipitation at thirty local areas in India during 2003-2006 alongwith humidity and temperature measurements and came out with GMWL for Indian subcontinent to be $\delta^{2} \mathrm{H}=7.93 \delta^{18} \mathrm{O}+9.94 \%$ o $\left(\mathrm{n}=274, \mathrm{R}^{2}=0.98\right)$ almost the same as GMWL and the difference is attributed to different in geographical and local meteorical considerations. They have given the earlier measurements also by different workers in the region. The measurements are the study covered all portion of subcontinent from monsoon from Indian Ocean i.e., in Bay of Bengal and Arabian Sea. The isotopic analysis was carried at NIH Roorkee using double inlet isotopic analysis (DIT RMS) and isotope laboratory at Vienna $\delta^{2} \mathrm{H}$ and $\delta^{18} \mathrm{O}$ were measured by Pt- $\mathrm{H}_{2}$ and $\mathrm{CO}_{2}$ equilibrium method following standard procedure. The detailed data set is available along with rainfall, temperature and humidity. They have also plotted meteoric water line at each location for all the regions and summarized in the table for both, the slopes and intercept at location which are given in Figures 7-10 along with the plot for each region and obtained isotopic composition by the method of Singh [7]. These are as following:

\begin{tabular}{l|r|r|}
\hline Station & Slope & Intercept \\
\hline Roorkee & 8.23 & 11.72 \\
\hline Lucknow & 7.81 & 6.5 \\
\hline Patna & 7.76 & 3.02 \\
\hline Sagar & 7.91 & 8.23 \\
\hline Allahabad & 7.5 & 4.4 \\
\hline Delhi & 7.2 & 4.6 \\
\hline Roorkee & 7.9 & 7.27 \\
\hline Lucknow & 6.75 & 3.31 \\
\hline Patna & 9.16 & 12.46 \\
\hline Sagar & 7.8 & 7.97 \\
\hline Allahabad & 7.5 & 4.4 \\
\hline Dellhi & 7.2 & 2.7 \\
\hline
\end{tabular}

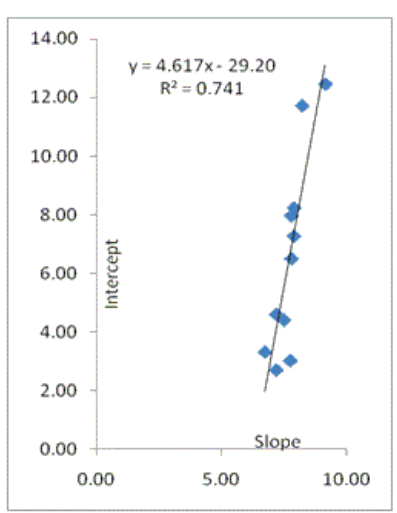

Figure 7: Showing the plot of slope versus intercept for Northern India at different locations in the region getting $\delta^{18} \mathrm{O}=-4.61 \%$ and $\delta^{2} \mathrm{H}=-29.20 \%$ as per interpretation Singh [7] composition of input precipitation in the region.

North region $\delta^{18} \mathrm{O}=-4.61 \%$, $\delta^{2} \mathrm{H}=-29.20 \%$ o

Western region $\delta^{18} \mathrm{O}=-9.29 \%, \delta^{2} \mathrm{H}=-63.73 \%$

Southern region $\delta^{18} \mathrm{O}=-3.10 \%$, $\delta^{2} \mathrm{H}=-14.52 \%$ o

Local region $\delta^{18} \mathrm{O}=-4.14 \%$, $\delta^{2} \mathrm{H}=-22.92 \%$ o

All the regions as per interpretation by Singh [7] are different and obtained original isotopic composition of precipitation. The graph 
Citation: BP Singh (2016) New Approach for the Analysis of Isotopic Composition in Precipitation Globally. Hydrol Current Res 7: 225. doi:

Page 6 of 7

between original isotopic composition of water in different regions between $\delta^{2} \mathrm{H}$ and $\delta^{18} \mathrm{O}$ as given in Figures 7-10 are plotted as given in Figure 11. This plot can be taken to be on GMWL of this part of continent which is given as $\delta^{2} \mathrm{H}=7.86 \delta^{18} \mathrm{O}+8.96 \%$ while GMWL $\delta^{2} \mathrm{H}=8.13 \delta^{18} \mathrm{O}+10.8 \%$. Measured slope is $7.86 \pm 0.20 \%$ o in place of $8.13 \%$ and intercept, $8.96 \pm 2.0 \%$ in place of $10.8 \%$ o taken to be same within statistical error.

\begin{tabular}{l|r|r|}
\hline Station & \multicolumn{1}{|l|}{ Slope } & Intercept \\
\hline Dabrani & 8.04 & 14.2 \\
\hline Devpraya & 8.07 & 9.54 \\
\hline Gangotri & 8.01 & 12.69 \\
\hline Gomukh & 8.22 & 17.12 \\
\hline Jammu & 8.11 & 9.29 \\
\hline Maneri & 7.31 & 4.84 \\
\hline Rishikesh & 8.47 & 10.43 \\
\hline Tehri & 7.94 & 9.37 \\
\hline Uttarkashi & 8.07 & 13.89 \\
\hline Nainital & 7.5 & 4.82 \\
\hline Dabrani & 9 & 21.25 \\
\hline Devpraya & 8.27 & 12.43 \\
\hline Gangotri & 7.73 & 6.21 \\
\hline Gomukh & 8.49 & 21.49 \\
\hline Jammu & 8.48 & 12.1 \\
\hline Maneri & 7.88 & 7.1 \\
\hline Rishikesh & 8.7 & 12.31 \\
\hline Tehri & 8.47 & 15.73 \\
\hline Uttarkashi & 8.23 & 14.37 \\
\hline
\end{tabular}

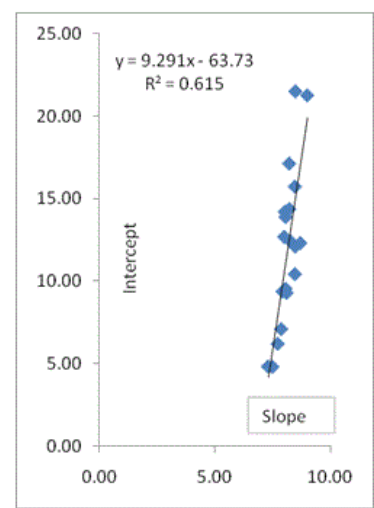

Figure 8: Showing the plot of slope versus intercept for Western Himalayas at different locations in the region getting $\delta^{18} \mathrm{O}=-9.29 \%$ and $\delta^{2} \mathrm{H}=-63.73 \%$ as per interpretation Singh [7] composition of input precipitation in the region.

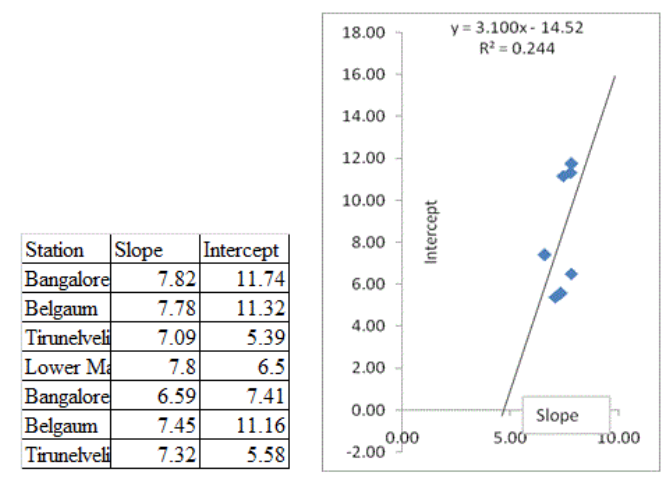

Figure 9: Showing the plot of slope versus intercept for Southern India at different locations in the region getting $\delta^{18} \mathrm{O}=-3.10 \%$ and $\delta^{2} \mathrm{H}=-14.52 \%$ as per interpretation Singh [7] composition of input precipitation in the region.

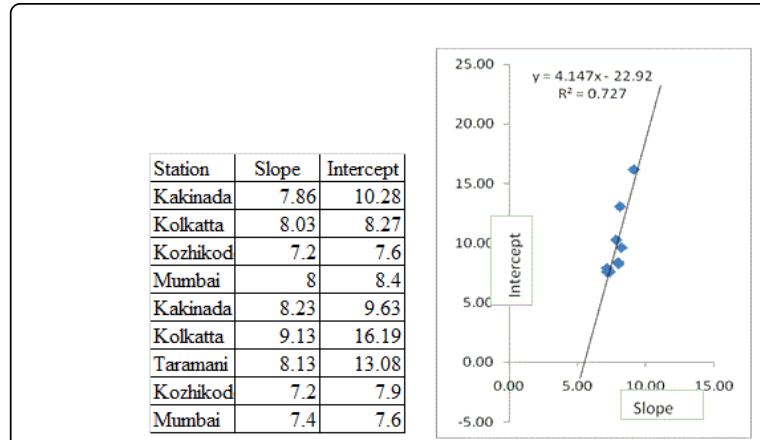

Figure 10: Showing the plot of slope versus intercept for Coastal Locations at different locations in the region getting $\delta^{18} \mathrm{O}=-4.14 \%$ o and $\delta^{2} \mathrm{H}=-22.92 \%$ as per interpretation Singh [7] composition of input precipitation in the region.

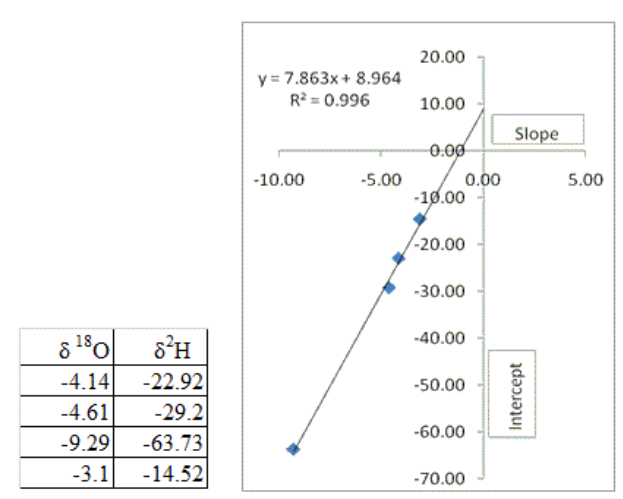

Figure 11: Showing $\delta^{18} \mathrm{O}$ and $\delta^{2} \mathrm{H}$ as obtained from different regions, Figures 7-10 giving the GMWL for the region.

Coastal region of Indian Continent and all the regions, the plot of slope versus intercept do fall on straight line suggesting that there are correlation within this region and locations. The GMWL by the present analysis for the regional can also be compared with the Kumar et al. [17] $\delta^{2} \mathrm{H}=7.93 \delta^{18} \mathrm{O}+9.94 \%$ with error of $0.20 \%$ of $\delta^{18} \mathrm{O}$ and $2.0 \%$ of $\delta^{2} \mathrm{H}$.

Therefore, we conclude that the plot of $\delta^{2} \mathrm{H}$ versus $\delta^{18} \mathrm{O}$ we get LMWL at each location, the plot of slope versus intercept of each location we get a straight line, suggested that the isotopic composition be correlated to give original isotopic composition and further the plot of $\delta^{2} \mathrm{H}$ versus $\delta^{18} \mathrm{O}$ of original isotopic composition of each region we get GMWL.

\section{Conclusion}

Three case studies are given with sufficient data for the analysis of precipitation for isotopic composition in different conditions.

(a) When plot of slope versus intercept of the region do not fall on straight line, scattered around to give two components with different origin.

(b) When plot of slope versus intercept do fall on straight line of different regions of the country with varying climate condition are 
Citation: BP Singh (2016) New Approach for the Analysis of Isotopic Composition in Precipitation Globally. Hydrol Current Res 7: 225. doi: $10.4172 / 2157-7587.1000225$

Page 7 of 7

such that points are all scattered around the straight line within the statistical error.

(c) When the plot of slope versus intercept are recorded to give rise to original isotopic composition of precipitation the region and plot of isotope $\delta^{2} \mathrm{H}$ versus $\delta^{18} \mathrm{O}$ of different regions to get GMWL.

Therefore, we find the plots of slope versus intercept of LMWLs in original isotopes method is to get the correct information of input of isotopic composition of precipitation in hydrological cycle so as to follow the precipitation.

\section{References}

1. Craig H (1961) Isotope variation in meteoric waters. Science. Deuterium content of natural waters and other substances. Geochimica et Cosmochimica Acta 4: 89-103.

2. Rozanski K, Araguas A, Gonfiantini R (1993) Isotope pattern in modern global precipitation. In: Climatic change in Continental Isotope Records Geophysical Monograph No. 78, American Geophysical Union, Washington. pp: 1-37.

3. Friedman I (1953) Deuterium content of natural waters and other substances. Geochimica et Cosmochimica Acta 4: 89-103.

4. Dansgaard W (1964) Stable isotopes in precipitation. Tellus 16: 436-468.

5. Yurtsever Y (1975) Worldwide survey of isotopes in precipitation. IAEA report.

6. Singh BP, Kumar B (2005) Isotopes in Hydrology, Hydrogeology and Water Resources. Narosa Publishing House, New Delhi, India.

7. Singh BP (2013) Isotopic composition of water in precipitation in a region or place. Appl Rad Isot 75: 22-25.
8. Singh BP (2014) Isotopic composition of river water across a continent. Appl Rad Isot 85: 14-18.

9. Singh BP (2014) isotopic composition of water in precipitation in the catchment areas of the river and in difference seasons. Hydrology Journal 37: 54-60.

10. Singh BP (2015) Isotopic composition of water in precipitation due to seasonal variation and variation in intensity of rain fall at a place. Appl Rad Isot 95: 72-75.

11. Singh BP (2015) Isotopic Composition of Water in Precipitation Falling at Different Altitudes. J Hydrogeol Hydrol Eng 4: 2-10.

12. Gonfiantini R, Roche M, Olivry J, Fontes J, Zuppi GM (2001) The altitude effect on isotopic composition of tropical rains. Chemical Geology 181: 147-167.

13. Ayalon A, Bar-Matthews M, Schilman B (2004) Rainfall isotope characteristics at various sites in Israel and the relationships with unsaturated zone water in Report GSI/16/04, Ministry of Natural Infrastructure, Geological Survey of Israel. Jerusalem. pp: 1-57.

14. Gat JR, Dansgaard W (1972) Stable isotope survey of the fresh water occurrences in Israel and the Northern Jordan Rift Valley. J Hydrol 16: 177-211.

15. Salati E, Dall'Olio A, Matsui E, Gat JR (1979) Recycling of water in Amazon Basin: an isotopic study. Water Resources Research 15: 1250-1258.

16. Gat JR, Matsui E (1991) Atmospheric water balance in a major basin in isotopic environmental model. J Geo Physics Research 96: 13179-13188.

17. Kumar B, Rai SP, Kumar S, Verma SK, Garg P, et al. (2010) Isotopic characteristics of India precipitation. Water resource research 46: 1-10. 